\title{
Interview
}

\section{Metadata, XBRL and regulatory disclosure - An interview with Gary Purnhagen, Principal of Gary Purnhagen Consulting}

\section{Gary Purnhagen}

is the Principal of Gary Purnhagen Consulting. He has been at the intersection of the SEC's modernization initiatives, technology, operations, marketing and sales for over 20 years helping issuers - public companies, and investment management firms and their service providers - investment banks, law firms, financial printers and Investor Relations firms respond and take advantage of regulatory and technology changes.

\begin{abstract}
Michael Moon interviews Gary Purnhagen, Principal of Gary Purnhagen Consulting on XBRL, the Security and Exchange Commission's initiative and the wide spanning implications of the adoption of this open standard on corporate disclosure and financial information supply chain.
\end{abstract}

Journal of Digital Asset Management (2010) 6, 72-82. doi:10.1057/dam.2010.5

Keywords: Gary Purnhagen; XBRL; metadata; financial printing; EDGAR

Correspondence: Gary Purnhagen Gary Purnhagen Consulting, 968 Lexington Avenue, New York, NY 10021, USA E-mail: gpurnhagen@ yahoo.com
MM: We're here with Gary Purnhagen of Gary Purnhagen Consulting. Gary, let's start off with a little bit of your professional background and what you did before you started your consulting practice.

GP: Sure, Michael. It would be a pleasure. I've been at the intersection of technology, operations, marketing and sales. Especially as it relates to the Security and Exchange Commission's (SEC's) modernization's initiatives over the last 20 years. I've advised issuers - both public companies and investment-management firms - both of whom need to provide disclosure information periodically to the SEC and their service providers - both advisors and document-processing firms - on how to respond, take advantage and manage the regulatory and technological changes that they're facing.

MM: Before you started your consulting firm, what kinds of firms did you work with before? GP: I've worked primarily in an industry that's referred to as 'financial printing'. Very few people outside of the industry or who are touched by the industry understand it. They provide a vital service to the issuers and their intermediaries that are involved with raising capital in the market or disclosing compliance documentation. While the term, 'printing', is still associated with them, and in fact, printing is often the end game of the service they're providing. Whether it's a mutual fund's semiannual report, or a public company's proxy statement the majority of SEC registrants outsource the process of submitting these documents to the SEC often to financial printers for the electronic filings to satisfy their regulatory compliance.

MM: So these would represent these often very thick, many thin pages that would be a prospectus or some other sort of description of an offering. It usually has a whole bunch of embargo criteria specific to a date of when it's released for public consumption. Is that it? GP: That's exactly right. One of the characteristics of the service requirement is that there's a compression of time for the client. They're paying a premium when they go to a financial printer, because the financial printer can work without schedules - providing 
whatever resources are required to get the job done to respond to a market condition or to respond to a deadline with the SEC.

MM: That's perfect, Gary. Financial printers such as Bowne and RR Donnelly; who are some of the other ones?

GP: RR Donnelly and Merrill along with Bowne are the three top firms. I've worked with all three of them over the past 20 years. MM: What's great about that as a point of reference for the readers here of the journal is that those particular companies - by definition of the compression of their cycles - the highly confidential nature of the information they're working with and the risk-consequence of screwing it up ... either as a function of a bad process or unauthorized disclosure of information. That means that these operations tend to be highly automated. In fact, oftentimes, they'd probably be early adopters of innovation, so as to keep compressing cycle time, production values, as well as security. Is that a fair characterization of that particular sector?

GP: You said it better than I did. It goes beyond time compression; accuracy and confidentiality are part of the three cornerstones of that service. Working in that industry, afforded me the ability to bring innovation to bear in the document processing phase to not only meet regulatory requirements but to take advantage of it. Whether it's the Internet or regulatory changes such as requirements to provide information electronically. And, by the way, they can also take advantage of the Internet for distribution of the information. So it provided me a wonderful training ground to be very much involved with the innovation of technology.

MM: Yes. As it specifically relates to innovation, what I find especially interesting about it all is that you've had to think through a lot of the technical issues of how you accelerate complex, multidimensional processes. And in a fairly unforgiving, 'Have to get it right the first time', environment. In any sense, the things that are now commonplace in that particular industry are now becoming what we might call 'next practices', for the broader industry of traditional marketing communications or sales enablement.
GP: Attributes such as need for speed or compressing timeframes, accuracy and confidentiality and distribution through multiple channels have all been cornerstones to the services that financial printers have provided and we see the demands for these attributes across the board these days. Particularly around document management on a granular level. With financial printing, it was typically on a page level. Now of course the demand exists to be able to 'tag' specific elements within a document. Particularly as it applied to the investment management community. Take Fidelity Mutual Funds. They have hundreds of different products, today. But across their spectrum of products, they have very similar language and very similar updates need to be made on an annual basis. So the idea of creating a digital asset library, allowing for better control for updates, propagation of common language across many entities and audit trails of changes becomes key to productivity.

MM: This is a great place to start to reprise us of the key developments and trends in financial reporting. Perhaps with an emphasis on disclosure and compliance. In the course of that, for some of us who may not necessarily be completely familiar with the term, 'disclosure', and things like that ... Give us a little one-sentence definition of what you mean.

GP: I'd be happy to. Disclosure really came about with the creation of the SEC, back in 1933. The SEC was created in response to financial scandals and the meltdown on Wall Street and the subsequent Depression.

MM: That sounds quite familiar. GP: It does, doesn't it? So we can expect further changes in the regulatory environment today. I believe that the topic at hand today, XBRL will play a significant role in the future. Back in 1933, the government realized that it was not protecting investors. It was stated back then that the best disinfectant was sunshine, which was the guiding principal to disclosure requirements. Disclosure really is about requiring that public companies and investment-management firms provide information so that investors can become knowledgeable as to the current state of the company. So this industry regulatory requirement for disclosure began back in the 
'30s. It's served us very well over the ensuing decades. There continue to be changes and additional rules. I think the next real milestone of importance came about in the early ' 80 s. The then SEC Commissioner Shad, who came from Wall Street, saw the immense inefficiencies at the SEC. In the early ' 80 s, he noted that there were over 10 million pages of information being supplied to the SEC annually. Only 13 per cent of those documents were being reviewed to any degree. Coming from Wall Street, Shad realized that technology could certainly help in this regard. So he proposed that we replace paper documents with electronic documents. That was the beginning of the idea around what's come to be known as EDGAR Electronic Data Gathering Analysis and Retrieval. While the documents were electronic there were no real changes to the format of the document. It was still a paper-based document. In this case, we were looking at new technology still mimicking the old. In 1993, the SEC was driven by the lowest common-denominator, so all companies could adhere to it. They required documents to be submitted in American Standard Code for Information Interchange (ASCII) format; looking very similar to a paper document, but being disseminated electronically.

MM: That would allow the submitting party to send off a floppy disk then - or a tape. And the receiving party - in this case, EDGAR would simply be able to read that data into a database with little or no human intervention in terms of having to fix data.

GP: Along with the physical media, telecommunications played a large role in how the information was submitted to the SEC.

MM: Sure.

GP: So they reduced the amount of paper they were receiving. Although it was interesting, often the reviewers at the SEC were reaching out to the companies and requesting paper copies. Because they still were not used to reviewing documents on screens. It was awkward. It was a sluggish system. Those steps brought us to the widespread use of the World Wide Web in the '90s. The SEC then made that electronic database available over the Internet. I think it became one of the most useful databases at that point in time that one could access through the world-wide web.
MM: As we start to move closer to the current state, what role if any did things like Sarbanes-Oxley (SOX) play in financial reporting, with an emphasis on disclosure? GP: Well, Sarbanes-Oxley ...

MM: I understand it's a tangential issue. But what, if any, significant impact was there? GP: SOX applied personal responsibility for the disclosed information and the process involved in the assembly of that information. MM: If you will, a chain of evidence. Or an audit trail in terms of who created what and changed what.

GP: Not so much a history of the development of the documentation as to an attestation to the accuracy of the information.

MM: As we start to bring in the fuller impact of the web on financial reporting, there are really two things I'd like you to address. One has to do with the evolving - perhaps rapidly changing - nature of the relationship that a company has with investors. Focusing on this notion of a real-time interactive relationship. And how that put, perhaps, additional stress on reporting more information. Then the compensatory or offsetting aspect of XBRL hopefully simplifying and speeding up companies' abilities to have interactive relationships with good, structured data as the basis of that relationship.

GP: As the web became more accessible to investors, companies realized this could enrich the communications with investors and indeed allow for features that were not possible before. So we saw many companies begin to provide a deeper look into their financials and operations. This did not change what was required to be reported. Go to an Investor Relations site of a major company and you will find a separate section that presents the filings made to the SEC. Elsewhere we see all sorts of enhanced communications techniques, from real-time stock quotes, investor presentations and calculators.

MM: In fact, Gary, I remember IBM was one of the first companies to create a microsite just for its interactive investor relations. They put into this microsite all kinds of calculators. I think they were Java-Script and/or calculators, by which you could do a year-to-year or quarter-to-quarter comparison of all of the various meaningful reporting metrics on the 
annual reports. The really served as a Ground Zero for the whole notion of, 'Wow. It's more than just publishing information. I'm actually publishing services by which investors and analysts can interact. Calculate. Kind of think out loud, one click at a time with the data that's on the page'.

GP: That's exactly right. Excellent new ways of taking advantage of the new technology. Moving beyond just posting static documents. Making the conversation more interactive with their investors. Now the reality of all of this is that as we were moving through the ' 90 s, more and more companies' primary investors were the large institutions, state pension funds and union pension funds, mutual funds and so forth. So investor relations began ...

MM: Not to mention that last one, of hedge funds. Right?

GP: This came about much later, but absolutely.

MM: Right.

GP: But we've digressed. Yes. We started to see new applications here. Then, of course, we began to see that those large institutional investors also began taking advantage of the web. Whether it was through a webcast on the earnings releases or taking advantage of a third-party data aggregator that's going out there mining this information. Still, the information was somewhat static - for the most part - from the SEC's website. So there was this vacuum that third-party data aggregators filled, where they were mining the data out of the SEC's EDGAR database, and then providing it to investors in a way that was more easily consumable. The problem with that was to make the information comparable for different companies within an industry, they were normalizing data. You brought up IBM as an example. A classic example of this is that in IBM's income statement; they have a line item that refers to their intellectual property and custom development. This is a very important line item for IBM. A third-party data aggregator combines that with other items to create a generic line item - 'income-other'. So that they could more easily compare IBM's story against somebody else. They're distorting the true picture of that company's profile. Now we're moving into an era where - with XBRL - Extensible Business Reporting
Language ... Companies can control the tagging of this information. The metadata. To be able to tell their story more precisely and more clearly.

MM: That brings up another key point. The notion of corporate reputations now being influenced by a lot of the things that are happening on the web. Some of which are things like briefings and webinars and those sorts of things. But also, other things happening in that social media space. Yahoo or MSN Money. Chat rooms. As well as other social networks where investors are basically communicating amongst themselves and really making the overall conversation as it relates to any one particular stock much more volatile and dynamic.

GP: So true. A fundamental problem with all of this is that these investors are going to places like Yahoo Finance or Microsoft Money and looking at the financial information on given companies that - again - this information has been normalized. In some cases, the way a Yahoo Finance reports on a given company's financials is very different to that actual company's financials. In some cases, particularly around one of the financial statements that's reported on a quarterly basis, with a document that's referred to as a company's $10 \mathrm{Q}$ - versus an annual report, which is a company's $10 \mathrm{~K} \ldots$ there's no similarity at all. It's hard to be able to tell where Yahoo Finance came up with these numbers. They're oftentimes taking four or five different accounting concepts and rolling them up into one, and getting it wrong. So there is a real problem associated with the fundamentals. There's a distortion if we look at this as a supply chain. And it is very much a supply chain, where this information is being generated within an organization and then packaged for external consumption. Then you have distributors taking this information and making it fit into their formats. Even if they are hammering a round peg into a square hole. MM: Another thing - this is also a larger backdrop that puts additional stress and complexity on this very notion of, 'How do I get transparency, and more specifically, true apples-to-apples comparison?' Specifically, I'm referring to the supremacy of intangible assets as now more than 50 per cent of total capitalization of publicly held firms. Specifically, 
if we look at total capitalization of all publicly held firms and then take out or subtract from that the book value of tangible assets of a company, you still have more than 50 per cent of total market capitalization directly related to intangible assets. By definition - intangibility they're unmeasured except as a grossed-up kind of funny number.

GP: Yes.

MM: This must just at some level drive Chief Financial Officers (CFOs) and their peers outside in terms of financial reporting and investment-management firms, absolutely nuts. Because how do you quantify the intangible? How do you make sense and how do you do comparisons of one company's intangible assets versus another's?

GP: Exactly right. So difficult. And it is adding so much time to the process of packaging one's financials for external consumption. It's not digestible, even, at this point in time.

MM: Would it be fair to say that the next 5, 10 or 15 years - much like the 5,10 or 15 years that followed from Franklin D. Roosevelt (FDR) in 1933 - is really going to be about bringing transparency and comparability to the domain of intangible assets? Creating a new way of modeling and reporting and tracking discrete categories of intangible assets? And more specifically, their contribution to the success of the firm?

GP: No doubt about it. And there's not a whole lot to add to it. It'll be interesting to see how it all unfolds. But a key here is in bringing it back to XBRL. This is an open standard in enabling technology that will allow us to begin to drill down. Not only to report this information in a transparent and accurate way, but even to understand it internally in a meaningful way.

MM: Let's do a little sidebar on XBRL. This is really the first mention of it. Now that we've got the context set, the largest context is, 'How do we start tracking the performance of intangible assets?' With the idea of marking out things like intellectual property or brand as a contribution to the overall market value of a company? And then specifically, how we have interactive investor relations, where we have to serve two groups. At least two stakeholder groups. One that are kind of looking for a long-term financial performance and of course the hedge funds that are looking for a short-term gain; to hell with the long-term consequence.

GP: Yes.

MM: So against that backdrop, then let's start to provide a short primer on XBRL. What is it? Why is it important? Who cares about it?

GP: Excellent. XBRL. Let's put XBRL into the context of historical perspective. When the initial EDGAR program was proposed back in the early ' 80 s, the SEC wanted to take advantage of tagging information within these documents. Back in the early ' 80 s, the only real open standard that could be useful was SGML. The accounting industry at that time pushed back and said, 'Impossible. There's so much flexibility in our US GAAP generally-accepted accounting principle that it would be impossible to standardize tags to indicate various accounting concepts such as net assets'. We could have five different definitions for net assets. So that idea was put aside until 1999. What's happened since then? SGML was the basis for HTML. And from that XML was developed and we started seeing wonderful applications associated with that. In 1999, some accountants and technologists got together and looked at what they referred to - correctly - a 'supply chain of business reporting information'. A supply chain not unlike any other supply chain. In this case, financial information is generated at the operational level. It gets refined at the internal financial reporting level, through general ledgers for controls and internal management. It then gets packaged for external consumption through financial reporting. It is then exported out of the organization where regulators and investment and lending partners are now using this information to make decisions. And eventually, it makes its way up on a macro level and influences economic policymaking. And they looked at the supply chain and they saw an extremely inefficient process in place. Not unlike many other supply chains before standardization came into play. Whether it was the shipment of goods before the standardized container came about. Or even the movement of goods on railroad systems before standardization of railroad ties. In that case, in the early 1800s, to move goods from New York to Chicago, you may have had to transport 
goods on three different rail systems, because of their proprietary railroads. Hence,

you had to unload and reload the goods.

Similarly ...

MM: That was also probably three different drayage contracts.

GP: That's right. That's exactly right.

MM: That, by the way, from a historical footnote, really brings us up to the stunning work of Robert Cossey and the theory of the firm. Specifically, the central role of transaction costs, in understanding complex things such as enterprises or supply chains.

GP: Exactly.

MM: And transaction costs being where there's a handoff from one party to the other. Whether there's an actual financial transaction or not is not so much. But there is a real cost associated with handoffs. And how many handoffs entailed to get something done ultimately translates into economic overhead that has to be serviced with revenue and profit.

GP: Particularly, if so much of that transaction is focused on preparing the handoff for the next stage. The person receiving the information hence, the consumer, then becomes a producer. Hopefully adding value. But so often, what's going on there is that that transaction is requiring a dump of information. Exporting down. Losing some context and some structure. And then a re-importation, which oftentimes is done by rekeystroking. You're right. The inefficiencies associated every step along the way are incredible.

MM: The principle of supply chains really drives from operations, research and logistics. Initially a concern of armies. How many rolls of toilet paper (TP) and cans of beans do I need to ship tomorrow, so that soldiers in a faraway battlefield - 5 weeks and a day - have enough TP and beans to fight the next fight. Right? GP: Yes.

MM: So the idea of a supply chain - or more specifically, the principal of a supply chain - is looking at an end-to-end process almost as a holistic or organic hull. Specifically, looking at the time and effort it takes to move through each stage of those handoffs. Identifying what they call the 'weak link'. Employing the theory of constraint. That is to say, 'The effectiveness of a supply chain comes down to the performance of its weakest links'.
Again, supply-chain theory is all about developing an end-to-end visualization, or an end-to-end model of how we move cans of beans and TP to a battlefield. Or how we ultimately provide accurate and timely information to investors. Looking for, then, the weak links. Where things break down and have high delays or latencies. Or high defect rates that require reworks and so on.

GP: That's right. Bringing it back to financial information, we saw weak links throughout the process. It was the passing of information from one disparate system to another system. Some large organizations might have had the money and might have been able to put the effort into standardizing around an Enterprise Resource Planning (ERP) system or a financial management system. But the concept here is, 'What if we standardize around the information itself?'

MM: Well, Gary - I want to use this as an opportunity to clarify one key point. When we mention, 'Information', a lot of people go, 'Oh, yes. I know what you mean'. I think we're using the term here in a particular and often-unique way. We're not just talking about the information. The dollars, cents and words. We're talking about the structure both of presenting it and organizing it. Specifically, of putting information in a particular analytic or consumption context. When we talk about this information supply chain, we're really talking not just about the flow of information, but of creating and maintaining a common structure of the information. Thereby, maintaining a context for understanding its meaning - as well as how it might support an analytic or investment decision.

GP: That is the cornerstone to XBRL, conveying the content and context for technology to be applied. Let's take a classic example. When we're preparing financial information for consumption - whether it's for regulators or analysts - it's coming out of a Hyperion system, which is highly structured and has context.

MM: Hyperion is going to be a business intelligence tool.

GP: It's a business intelligence tool.

MM: It's grabbing data out of production data systems. An ERP system. A supply-chain management system. Bringing it into a particular 
set of analytic capabilities by which to start slicing and dicing it in ways that the original systems couldn't support.

GP: That's right. We have that intelligence applied to the information. But then companies are distilling it down to Excel worksheets for further massaging, which still have some structure to it. But then for the SEC, and for distribution, we're distilling it down to PDF and HTML. If we read the document, we can get the sense of content and context. But for a computer, it's useless. Hence, with XBRL, we're allowed to standardize around data. We're maintaining content and context. And we don't lose that as we move from system to system.

MM: Fabulous. That introduces another key distinction that frames the value proposition of XBRL. That is information in and of itself has little or no value. Even structured information has little or no value without a social context where human beings consume and interpret and take action on it. So the social dimension of information ... The social context of information ... is what imbues information with value and meaning. Therefore, a cornerstone - a key tenet - of XBRL - is maintaining a persistent social context of consumption of information. Inherent in the structure of the metadata - inherent in the logic and the propositions of the logic - is the notion of, 'There's a relationship between producers and consumers'. In this case, it's between publicly held firms and their investors. And somehow there's a set of assumptions, as far as what's meaningful or more meaningful or less meaningful in the context of that social relation. That is inherently embedded like a flat-world-round-world. That's embedded as a paradigmatic assumption of XBRL. It's really about empowering a relationship between someone who's obligated to report information in a transparent way, and someone who wants to take that information and use it in a manner that makes sense for him or her.

GP: Exactly right. And if we observe the 'supply chain' of, in this case, business reporting information, the role of producer/consumer is joined. As we take in information we are consumers, but it never just ends there; we consume information to produce some value. So throughout the supply chain all involved are both consumers/suppliers. As an open standard, XBRL facilitates collaboration and sharing of this financial information more quickly. It thereby shortens the information/knowledge cycle. It facilitates the consumption of information and allows us to pass on the information in a more effective manner because we no longer have to worry about the conveying of the context/content value add. All this allows for a better focus on the social aspect of this knowledge. It also allows extending that value beyond the internal organization. Allowing it, again, to create knowledge not only on that given organization, but also on a larger macro level. Whether it's industries, exchanges or even countries.

MM: So in this context, when we look at $\mathrm{XBRL}, \mathrm{XBRL}$ in the most prosaic of terms is basically a set of agreed-upon conventions for how to tag individual elements of a $10 \mathrm{~K}$ or $10 \mathrm{Q}$ or other corporate action. So it's an agreement among people that have to report that, 'We're going to tag this element - this piece of information - this piece of data - in a structured and uniform way, using a common label or metatag for identifying and marking out a particular element'.

GP: Well, yes and no.

MM: Great! What didn't I get right?

GP: XBRL, as an enabling technology and a standard, is accounting-standard agnostic. But the agreed upon tags are accounting standard specific. So we still have barriers in place because the tags are specific to US GAAP or Canadian GAAP or International Financial Reporting Standard. Each one of these standards has its own taxonomy. But it's a step in the right direction and it should help in the ultimate convergence of accounting standards. But as with the US GAAP principles, we are not forcing a company to standardize how they report information. We're looking for them to adopt a set of standards and hopefully not have so many unique, extensible elements that it reduces comparability. In fact, I was speaking with a gentleman today from a one-of-a-kind company that's a uranium enrichment company. They have concepts that they report that are unique to their... You can't even say 'industry ...' Because there are all of four companies in the entire world that do this type of work. So they're going to have 
unique sets of reporting elements. But to a large degree, an analyst can look at this information, understanding its content and context.

MM: Then irrespective of what accounting principles or standards you're using, XBRL allows us to tag information in a fairly uniform way. Such that we can start doing more accurate, timely side-by-side comparisons of one company versus another in a similar industry or sector.

GP: That's correct. What we're seeing, looking specifically at XBRL with US GAAP is an increase of elements within the taxonomy. Three years ago, a company tagging their primary financial statements using the US GAAP taxonomy, on average would have to create about 30 extensions. Today, using the current US GAAP taxonomy, an average company ... It varies, depending on industry. It has to create about 10 extensions.

MM: Do these extensions show up in a material form as a footnote?

GP: Actually that average is for the primary financial statements. For footnotes and schedules for a company's financials we will probably see a far greater number of company elements or extensions.

MM: So these would be separate line items in a balance sheet or income statement.

GP: Correct. What ties this all together to the accounting principles is that an element within XBRL also allows us to reference back to the authoritative reference. So that we understand the accounting concepts behind that line item. But now we can apply technology to keep track of that. For instance, a company might report the accounting concept 'cash' But what exactly do they mean? Is it cash and cash equivalents? Or something else? Are they one in the same? Today, we figure that out by researching the footnotes, which is a time consuming process. With XBRL we can allow technology to sort all of that out.

MM: I want to introduce another concept of business model performance. Because it will allow us to look at XBRL in a really strategic context. Following the work of Adrian Slywotski of Harvard Business - now Mercer Management Consulting ... In a book, he came out within the mid-'90s ... I think it was called, 'Value Migration'. He introduced the notion of how you identify and track the performance of a business model. He offers a very compelling and quantitative approach where you look at, for example, computer companies. There you'd look at Apple, Dell, HP, IBM, Toshiba and maybe another company. You look at their total market capitalization. So you take the total market capitalization of all six or seven firms in that category. Let's say you came up with total capitalization of a trillion dollars. It's probably more than that, but I'll just take a nice, round number. Over time, by quarter, you track individual companies' relative share of total market capitalization. Over time, it's clear that Dell has done nothing but bleed market capitalization. And to Adrian Slywotski's point, it's proof positive that they have a failing business model. If you look at HP, they've always been maintaining. Now when you deconstruct HP's financials, you'll see that financial services is the real money maker. And hardware is kind of an on-again, off-again money maker. And their PC division really isn't much of a net profit contributor. But then you look at Apple. Apple's done nothing but gobble up total market capitalization - like a Pacman gone crazy.

GP: Yes.

MM: When you look at the last 10 years, Dell has probably given up 80 per cent of its value, and Apple has largely been the recipient of it. In fact, when you look at total market capitalization of Apple this last 10 years, their share has gone up by a factor of 9 or 10 . So the idea then is that what we're talking about now ... XBRL is going to allow us to have dashboards that track relative business model performance at the level of total share of market capitalization. And because of the higher level of accurate typing, I'm really going to be able to pull out the underperforming, as well as the superperforming aspects of a business, and correlate that to what every investor wants to know - which is future free cash flows. And are they going to be beating up or get beaten up. Are they going to be having lunch or be lunch in tomorrow's marketplace.

GP: Key to the overall objective of XBRL is to facilitate the comparability among companies within industries. That facilitation is a result of technology interacting with tagged data. With this information being tagged and made 
available, the preparation - the calculations of those formulas - can be automated. In fact, we could set it up right alongside our watch list of companies we follow And as information is being updated with the SEC, we're consuming that information. It's updating our dashboard, and we're getting as close to real-time understanding of what's going on. That truly levels the playing field. The hedge fund guys out there who are trading on the fact that they're smarter and quicker to be able to create these performance models - now; technology is sort of leveling the playing field, somewhat. It's going to be interesting.

MM: Now there's one other dimension to this dashboard and business-model performance as it relates to the effects of XBRL in this whole financial reporting-and-disclosure process. It's the idea of social media monitoring. Now we have these services that call through blogs, forums and discussions. They summarize tens of millions of daily conversations as they relate to a particular company. A particular brand and a particular market. Summarizing things like sentiment - positive sentiment - neutral and negative sentiment - as well as meaningful shifts in opinion, pro or con, relative to the adoption or non-adoption of particular products. These are happening in real-time. It parallels a lot with what Google has done in their Google Flu Watch, where they look for keywords and phrases across local language sorts for pathology-related answers. They're able to identify hotspots in terms of communicable diseases 4, 5 or 6 weeks before WHO or the National Disease Control Center can identify it. So social media monitoring now is bringing back structured - almost real-time - data and information about who's saying what. Pro or con. That's now going to be part of the analytic data set that supports this real-time monitoring of what's going on in my company in the context of this larger ecosystem in which I operate.

GP: XBRL will allow for web services that can automate our researching financial information. We will then be able to track what types of information investors are seeking. Hence, we'll be able to determine on a macro level what the current investment criteria in vogue are. And I think it will contribute to the overall social discussion as to the valuable metrics to investing and determining value.

So yes, I think we'll be able to start looking at it on a larger macro level, and start to understand the dynamics of market movements in ways that we're not even envisioning today. MM: You just said something, Gary, that just blew the top of my head off. Let's look at just M\&A as a large area. What were the preceding events as characterized in data, that led to a particular class of M\&A? It wouldn't take any more than a couple or 3 or 4 years of that kind of data to develop meaningful, predictive models of who's going to get acquired next, based on these particular financial relationships and dynamics.

GP: This is what I love. This is what excites me. Now we're realizing that with this new technology, we can begin to do things that we could never envision before. You're absolutely right. The applications are going to be mind-blowing in terms of predictive modeling. Recognizing the power of metadata. It's the power of being able to work with this and not worry about the cost of setting up this information so we can begin to do some of these things that we're talking about. In fact, we are in the early stages of developing taxonomy for Corporate Actions to be able to leverage technology in the predicting and decision making surrendering investment decisions.

MM: As we begin to move toward the end of our conversation, I'd like to loop this back to the idea of digital assets. We've been talking about XBRL kind of 'inside looking out'. From, 'How do I publish financial information and how does that compare-and-contrast with others in my industry or sector?' That's all good. But now let's take an inward look. I'm a CFO of a large organization. I've got this analytic dashboard that's basically giving me my daily comparables out there in the industry. I'm tracking who's saying what about my stock with social media monitoring. But now take me into how this gives me a new level of transparency to what's going on in my organization that I'm not getting through my standard business reporting internal controls. GP: For XBRL to apply here, we will have to see it embedded throughout an organization. Eventually, XBRL will be tagged at the point of sale, and throughout the organizations 
intelligence chain. Today, within an organization a lot of effort is involved with attempts to unlock the knowledge within their systems. Once we have metadata on all of our information, financial and otherwise, then our ability to extract knowledge will move to levels that are extremely hard to achieve today manually.

MM: Let's just kind of knock off a couple of those categories of really meaningful, potentially strategic categories of information that are currently not included at the high level summarization of a business. Clearly we have operational Customer Relationship Management (CRM). What's going on in my call center? Who's complaining about what? What's broken? What needs to be fixed. Right?

GP: It's making all of the organizational information accessible. We are still a long way from that but essentially, we're talking about what is the dream dash board for an executive: sales trends, social media tracking, what are your clients saying, and what are your employees thinking is wrong with the process. MM: That's great, and that's all still part of that financial information supply chain. I guess I want to get outside of that, into the other areas of the organization. Specifically, what are CFOs looking for? Well, CFOs - at the end of the day - are your chief risk officers. Right? They're constantly looking for the 'gotchas' and trying to get out in front of it before someone outside says, 'Hey ... Did you know that this is going on in your organization, and that's bad?' Right?

GP: Yes.

MM: So another thing that would be part of this overall structured information would be taking some of the web analytics, which at the end of the day is pretty crude. It just gives reports on a whole bunch of anonymous information or anonymous users. But eventually, those web analytics are going to be wrapping around customer personas and subscriber-type profiles. I think it'd be really interesting to start seeing some of those heat maps - vis-à-vis the web analytics - now informing the risk-management and resource-allocation issues that a CFO constantly has to deal with.

GP: Absolutely.

MM: The idea then is that XBRL is not just about financial reporting. Yes, it's about that.
But it's also about bringing structure and social context to whole other areas of information that right now are largely opaque and/or trapped in systems that are doing their production workflow or process just fine, but not necessarily producing strategic insights. GP: We are now talking about metadata. XBRL will help us with business information, which is today focused on financial information. It will expand to other information as required by investors and regulators and internal consumers. It may well be the catalyst to demonstrate the value of metadata where we then start to apply effort to the metrics of intangible information.

MM: So as it relates to the specific narrow or arcane area of digital asset management which is largely, 'How do I apply metadata and policies to reusable media and text files?' It's conceivable that in the future - not tomorrow, but maybe the day after tomorrow that part of the overall analytic datafeeds for this overall corporate performance dashboard is, 'Who's interacting with what assets? And thereby, what is the economic value of these individual assets as they relate to corporate performance?' So were these assets used in customer-facing experiences of the brand or product? Or did they support internal communications? Training? Support functions that are part of our overall productivity? Because we're now starting to get more structured financial information - including things like activity-based accounting associated with those assess - it's quite conceivable that we will have not only the rigor, but also the capacity to start tracking the economic performance of these digital assets. Files characterized by metadata and policies. GP: And which constituencies are interested in what information and where is the value proposition at each stage of the process. MM: This one last thing, I'd like to get your take on. That's the notion of a digital persona or a customer persona. The sad fact is that most companies today do not know with any degree of accuracy the number of customers they have. They have database records that may or may not correspond to a customer. And they have CRM systems that have all kinds of records in them. But at the end of the day, it's missing the critical distinction between a customer 
record - in the context of a household or a business entity - or a buyer - a parent or whatever. And the user or the stakeholder or beneficiary of that purchase. So it seems to me that most companies today are rearing their heads up out of the muck of CRM and going, 'Wow! I really don't know how many customers I've really got. And more importantly, I don't know the economic value of any one customer relationship'. So as companies begin to think through and put into place multi-channel analytic capabilities, where they can really identify with accuracy the number of customers they have ... As well as the economic value in terms of future revenues likely derived through predictive modeling that this particular customer relationship will provide ... We're then on the cusp of saying, 'Well, gee - this customer-engagement object this digital persona that has not only your name and identity and transaction history ...' It also has things like, 'Here's the number of terms you've walked into our store and visited our website, downloaded a coupon, et cetera, et cetera'. As well as, 'Here are all the various means that you want to touch us with'. You're an iPhone user or a Blackberry user or whatever. You're a MAC guy versus a PC guy. Et cetera, et cetera. Your preferred browser is Firefox. As we start to look at that customer in the context of structured data, and your consumption of this structured data and services, it then becomes quite feasible to start thinking about, 'Huh ... How about if we start modeling in real-time not only the relative change in the number of actual customers we have, but modeling in real-time future free cash flows that result from individual customers? And then aggregate it up through consumption cohorts, segments, markets and industries'. It seems to me that XBRL can and will play an instrumental role in that level of detailed reporting of customer relationships. And how related and/or engaged they are with us as a company and a stakeholder.

GP: The scenario you are presenting is similar to the implementation of the UPC. An open standard that at first was implemented to address the pricing of individual items, but very quickly the participants in the supply chain realized that it could bring so much value throughout the supply chain. Now this standard can allow a company to track sales, tie to back to inventory and even to marketing opportunities - where are products selling, by whom; and with other marketing data tie it to demographics to realize opportunities and business trends.

MM: Right. This brings us back to the coda for XBRL. When you ask the question, 'What kinds of things does XBRL as a schema describe, using some form of taxonomy?' Well, it describes businesses. Business entities. Business entity relationships. Roles and responsibilities of individuals. Products. Brands. Lines of business. Currencies. Currency exchange rates. Key suppliers. Key supply contracts. Or longterm supply contracts. Things like intellectual property, et cetera. In many respects, XBRL gives us a fairly uniform way of describing, with structured information, an entire business ecosystem.

GP: Yes. Focusing primarily, as well, on the relationship among all of those components in that ecosystem.

MM: Right. Which was the missing, critical link for unlocking the full value of business intelligence.

GP: Exactly.

MM: This looks like a good place to conclude. But before we do that, any last summary remarks in terms of things that we've touched on that that may be forward-looking statements? GP: I think our conversation has transcends XBRL. Not to take away from the significance of this standard, but we have been speaking about the potential value to metadata and the value that can be realized from organizations that begin to think about the information that is contained within their organizations. As organizations understand the potential of this value and implement the technologies that will allow them to tap into this asset, the return on investment will be fantastic. Not only for the organizations but for all stakeholders improving the overall experience of the producers, their partners - suppliers and consumers as well as their investors.

MM: On the basis of the Journal of DAM and Gistics, thank you so much. We look forward to seeing you at the next XBRL conference. GP: Likewise. Michael, thank you. This has been a great experience.

MM: Cool. 